\title{
The challenge of evaluating the effects of web-based crime mapping on cooperative policing intervention
}

\section{Background}

The premise behind cooperative policing intervention is that crime prevention should not be the exclusive responsibility of the policethe community should also get involved. In recent years, many WebBased Crime Maps (WBCMs) have been developed as tools for cooperative policing intervention for the purpose of reducing crime by enhancing public awareness. For example, a survey conducted in 2010 found that the police agencies of 48out of the world's top 100 cities with the highest GDP provide web-based crime mapping on their official websites. ${ }^{1}$ WBCMs are web-based solutions that visualize crime information on a digital map accessible by the public. Whether the WBCMs are successful in reducing crime is still debatable - we explain this as follows. WBCMs have drawn considerable public attention. A notable case was the launch of UK's online crime mapping website. When the street-level crime map service went live in February 2011, it recorded up to 18 million hits per hour on the first day of its high-profile launch, more than any government website has ever tried to deal with., ${ }^{2,3}$ More and more WBCMs have been developed in the market in recent years. For example, Crime reports, an online crime mapping service provider, had over 800 law enforcement partners across North America as at June 2010. The popularity of WBCM applications lets more and more users from the general public get access to the information from WBCMs. However, a practical concern of WBCMs is that it may lead to unintended consequences in regard to spatial-temporal crime patterns. Therefore, evaluating the effects of WBCMs on spatial-temporal crime patterns is important because the findings can tell whether or not the intended intervention's objectives are met.

\section{The challenge}

Although evaluating the effects of WBCMs on spatial-temporal crime patterns is important, it faces several challenges. A key challenge, among others, is its dynamic nature. The following example is provided to illustrate the challenge. Given that a web-based crime map (WBCM) is accessible by the public, the possible interactions between a WBCM and spatial-temporal crime patterns (for simplicity, the "interaction" in the following) can be highly complex as illustrated in a dynamic cycle in Figure 1. In the cycle, the contexts of different users (such as their backgrounds, intentions, knowledge and reactions) are different, so they react differently to the received crime pattern information from the WBCM. The results of their behaviour are reflected by the crime distribution. Moreover, crime distribution is also affected by general trends, periodic variations, and policing intervention. The crime distribution is then recorded, processed and displayed as crime patterns on the WBCM. Moreover, the WBCM is updated periodically according to the latest crime distribution, and then the above cycle continues.

\author{
Volume 2 Issue 3 - 2016
}

\author{
Stephen CF Chan,' Kelvin Leong ${ }^{2}$ \\ 'Department of Computing, the Hong Kong Polytechnic \\ University, Hong Kong \\ ${ }^{2}$ North Wales Business School, Glyndwr University, UK
}

Correspondence: Stephen CF Chan, Department of Computing, the Hong Kong Polytechnic University, Hong Kong, Email stephen.c.chan@polyu.edu.hk

Received: February 14, 2016 | Published: April 13, 2016

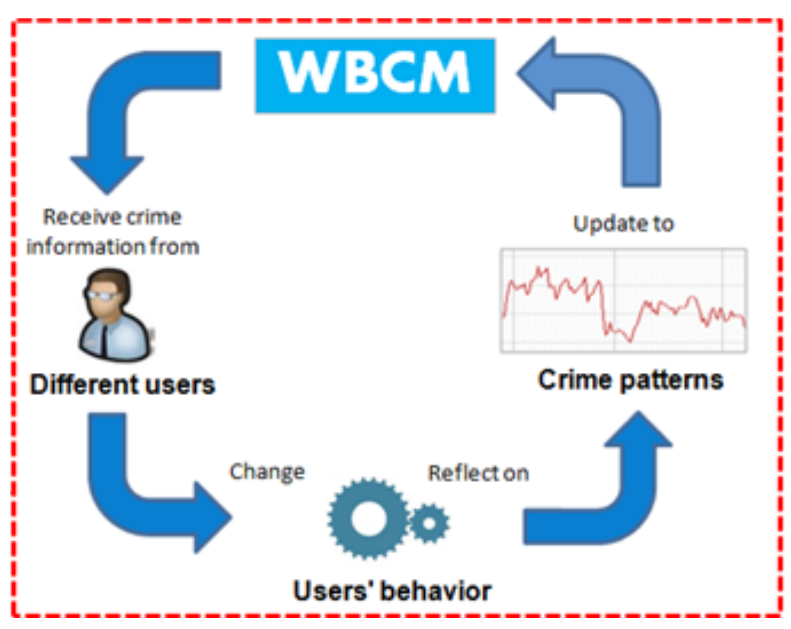

Figure I WBCM-spatial-temporal pattern interaction cycle.

\section{Acknowledgments}

None.

\section{Conflicts of interest}

The author declares that there are no conflicts of interest.

\section{References}

1. Leong K, Chan S. A content analysis of web-based crime mapping in the world's top 100 highest GDP cities. Crime Prevention \& Community Safety. 2013;15(1):1-22.

2. Chainey S, Tompson L. Engagement, Empowerment and Transparency: Publishing Crime Statistics using Online Crime Mapping. Policing. 2012;6(3):228-239.

3. UK Home Office. Business plan quarterly data summary. UK Home Office, London. 2011. 